\title{
Use of finite-element simulation of primary deformations within walls of discharge tunnel to present anthropogenic disasters
}

\author{
Lyapota Taras L. /Candidate of Technics, associate \\ professor \\ FSBEI HE Platov South-Russian State Polytechnic \\ University (NPI) \\ Novocherkassk, Rostov region, Russia \\ e-mail: taras_1ll@mail.ru
}

\author{
Bandurin Mikhail A./Doctor of Technics, associate \\ professor \\ FSBEI HE Platov South-Russian State Polytechnic \\ University (NPI) \\ Novocherkassk, Rostov region, Russia \\ e-mail:chepura@mail.ru
}

\author{
Volosukhin Victor A./Doctor of Technics, professor \\ FSBEI HE Platov South-Russian State Polytechnic \\ University (NPI) \\ Novocherkassk, Rostov region, Russia \\ e-mail: ngma_str_meh@mail.ru
}

\author{
Mikheyev Alexander V./Candidate of Technics, associate professor \\ FSBEI HE Platov South-Russian State Polytechnic University (NPI) \\ Novocherkassk, Rostov region, Russia \\ e-mail:avmih@mail.ru
}

\begin{abstract}
The results of simulation of finite-element state for stressed and strained changes under different failures of hydraulic structures are given. As a result of the experiment, a solid-state model of bearing elements was built. Stressed and strained state of reinforced concrete bearing elements of the discharge tunnel for the shaft spillway of the earth dam under different load combinations is considered. An intensive threshold of danger to form longitudinal cracks and defects in the course of computations of the moment-free profile of the structure is determined; it is shown that when using the pipes with rational cross-section form, saving in the material (rein forced concrete) achieves twenty five percent.
\end{abstract}

Keywords-finite-element, discharge tunnel, anthropogenic disasters, climatic changes growth.

\section{INTRODUCTION}

The problem of a possible closure of river beds under different kinds of natural landscapes disturbances and assessment of consequences from break of a such blockage to prevent disasters under the conditions of the growth of climatic changes is urgent enough, but it is not studied in home and world science and practice. A discharge tunnel computation was carried out by a software complex SCAD office, which operation is based on the method of finite elements and superelements. Stressed of wained state of reinforced concrete bearing elements of the discharge tunnel is considered. Disarrangement of joints between the elements of fabricated structures (especially between pipe links, tower members, attachment slabs, bulkhead blocks) is simulated. The disarrangement is observed for $40 \%$ of structures; ground washing on the structure counter is fixed for $45 \%$ of structures; moreover, to repair consequences on similar structures about $30 \%$ of the construction cost is spent.

\section{MATERIALS AND METHODS}

Spillway tunnels of rectangular, square or round outlines are used in the shaft spillways of low-head earth dams designed for discharge of excess flood waters [1, 2, 3]. Depending on water discharge tunnels can be one-eyes, twoeye, three-eyes and four eyes. More economic form of crosssection is, as it is known, section in the form of a circular arch allowing decreasing bending moments. The discharge tunnels can constructively be made monolithic or of segment blocks presenting themselves a part of a cylinder jacket. Structures of shaft spillways are subjected to action of the vertical load, so the cross-section axis of the discharge tunnel (arch) will be rational if its outline changes according to the law of the girder moment change. Therefore, a prospective direction is search of the rational (moment-free) section outline for the discharge tunnel (figure 1).

In figure $1 q_{x}, q_{y}$ - distributed horizontal and vertical load. 


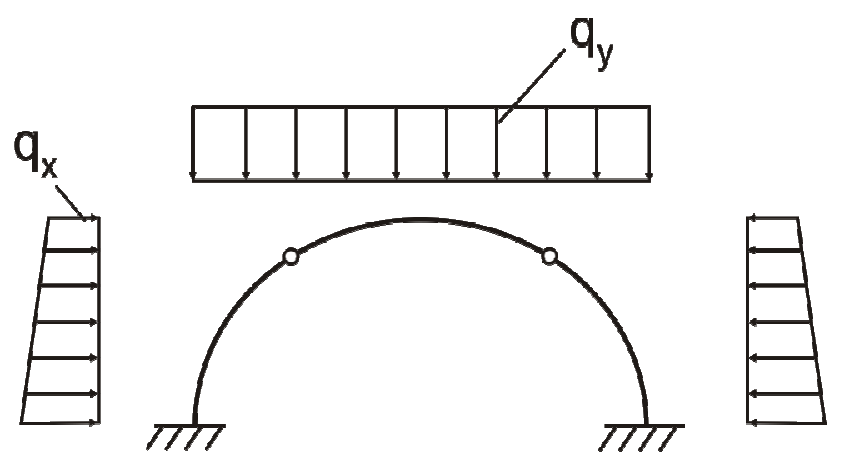

Fig. 1. Calculation scheme of the culvert.

An example of computation for the moment-free section of the discharge tunnel of segment blocks with joint coupling that was carried out by a soft-ware complex SCAD office is given in the article (figure 2) [4].

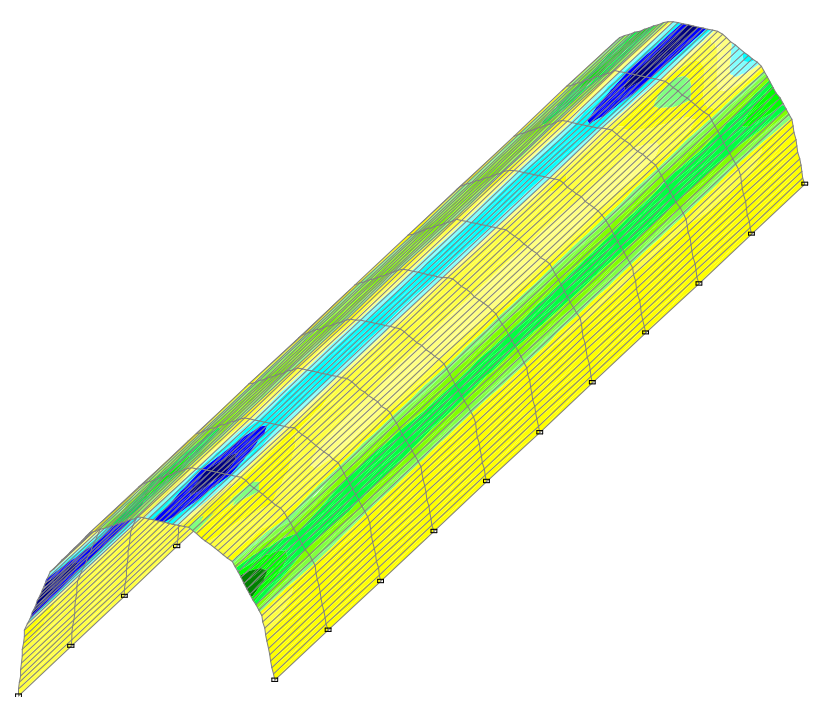

Fig. 2. Diagram of initial movements within the walls of the discharge tunnel.

Loads and interaction of structure elements are specified under the most unfavourable conditions for construction and operation periods.

Permanent loads (weight of the discharge tunnel itself, soil and ground water pressure) and short-run loads, hydrostatic and pulsation loads were taken into account when computing.

Design load was taken as an evenly distributed load without lateral soil pressure taking into consideration. Using the generalized relations given in [5], expressions to computate coordinates of the moment-free section for a pipe culvert [6] were received:

$$
\begin{gathered}
y=1 /\left(1-k^{2}\right)^{1 / 2}\left(\left(2-k^{2}\right) / 2(F(k, \pi / 2)-F(k, \psi))-(E(k, \pi / 2)-E(k, \psi))\right)(1) \\
y=1 /\left(1-k^{2}\right)^{1 / 2}\left(1-k^{2} \sin ^{2} \psi\right)^{1 / 2}
\end{gathered}
$$

where $F(k, \psi)$ - elliptic integral of 1 types;
$E(k, \psi)$ - elliptic integral of 2 types;

$k$ - the module of elliptic integrals;

$\psi$ - the amplitude of the elliptic integrals.

The stresses in the moment-free profile associated with the module of elliptic integrals addiction:

$$
\sigma=\gamma_{f} \rho_{g} g h_{0}^{2} / 4\left(\left(1 / k^{2}\right)-1\right) t
$$

where $\gamma_{f}$-reliability coefficient on loading;

$\rho_{g}$ - consistency of the soil;

$g$ - acceleration of gravity;

$t$ - thickness of the segment block.

Decision algorithm:

1. Are known the specific weight of soil $\gamma_{g}=\rho_{g} g$ coefficient $\gamma_{f}$, filling height $H$ и $h_{0}$, coordinates of boundary points $x_{k}$ и $y_{k}$.

Let us calculate the relations:

$$
x_{k} / h_{0} \text { and } y_{k} / h_{0}=H / h_{0} .
$$

2. Follows from expression (1) that:

$$
x_{k} / h_{0}=f_{1}(k, \psi) \text { and } y_{k} / h_{0}=f_{2}(k, \psi) .
$$

The nonlinear equations solve by a numerical method calculating $k$ and $\psi_{k}$.

3. Changing $\psi\left(\pi / 2, \psi_{k}\right)$, calculate coordinates of a form of a spillway tunnels:

$$
\begin{gathered}
y=1 /\left(1-k^{2}\right)^{1 / 2}\left(\left(2-k^{2}\right) / 2(F(k, \pi / 2)-F(k, \psi))-(E(k, \pi / 2)-E(k, \psi))\right) \\
y=1 /\left(1-k^{2}\right)^{1 / 2}\left(1-k^{2} \sin ^{2} \psi\right)^{1 / 2} .
\end{gathered}
$$

4. Calculate the stresses in the moment-free profile a spillway tunnels:

$$
\sigma=\gamma_{f} \rho_{g} g h_{0}^{2} / 4\left(\left(1 / k^{2}\right)-1\right) t .
$$

Results of comparison of profiles of spillway tunnels of a circular and moment-free outline are presented in figure 3.

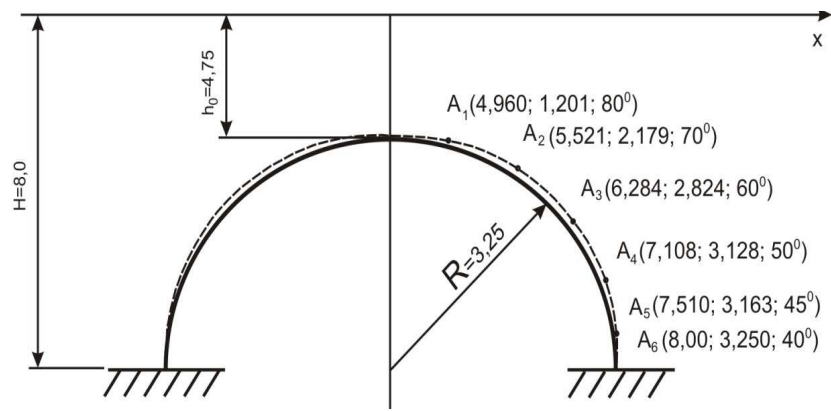

Fig. 3. Comparison of profiles of circular and membraneless outlines of culvert tunnels.

Correlation of computation results for discharge tunnel sections of semicircular outline and the moment-free one 
showed that deviation in design points is $6-8 \%$ by the axic of abscissas under the tunnel depths $6-10 \mathrm{~m}$ and its radius of cross-section axis is $2,75-3,75 \mathrm{~m}$. The similar result [7] was received when correlating the sections mentioned, but with the lateral soil pressure taken into account. From correlation of a computation results it follows that the cross-section axic of discharge tunnel is close to the axis of the semi-circular section. Therefore, the rational cross-section form of the tunnel is close to the semi-circular one and depends on the relationship between intensities and soil vertical and lateral pressure. Giving to the discharge tunnel cross-section outline close the rational one will allow to reduce essentially the value of stresses and therefore consumption of materials [8]. Strength analysis of the cross-section considered shows that reinforced concrete saving only for a fabricated water conveying tunnel of semicircular outline will total from 37.5 to $151.6 \mathrm{cbm}$ for one structure depending on a diameter as compared with typical rectangular elements $[9,10]$ for water.

Movements by the horizontal and vertical along bearing elements show insignificant displacements in support zones of horizontal reinforced concrete elements (figure 4, 5, 6).

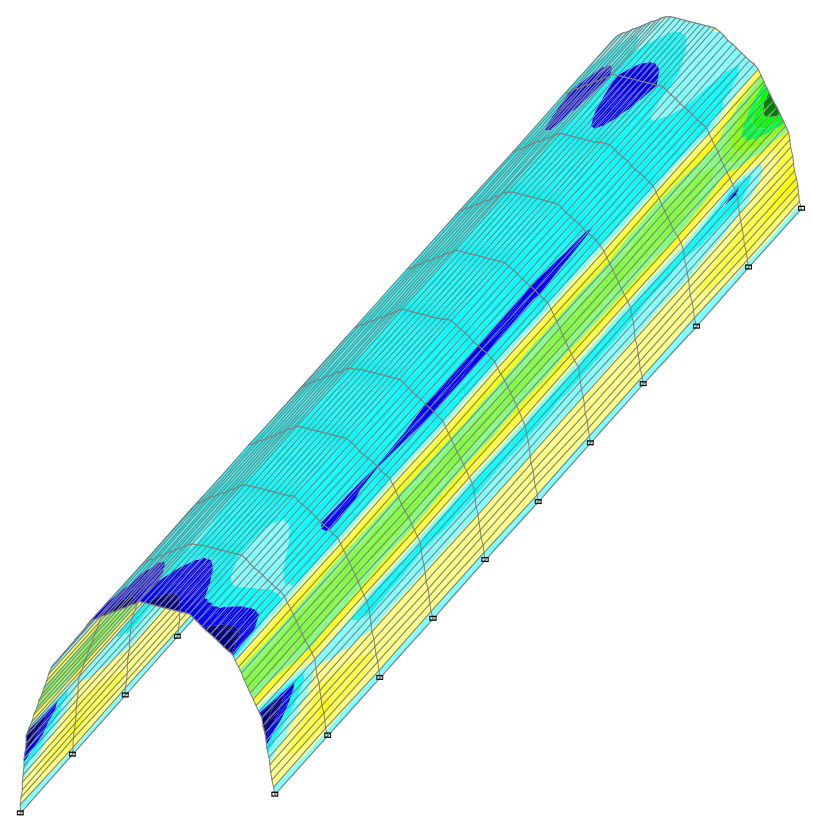

Fig. 4.Diagram of defect movements by the horizontal along the discharge tunnel length.

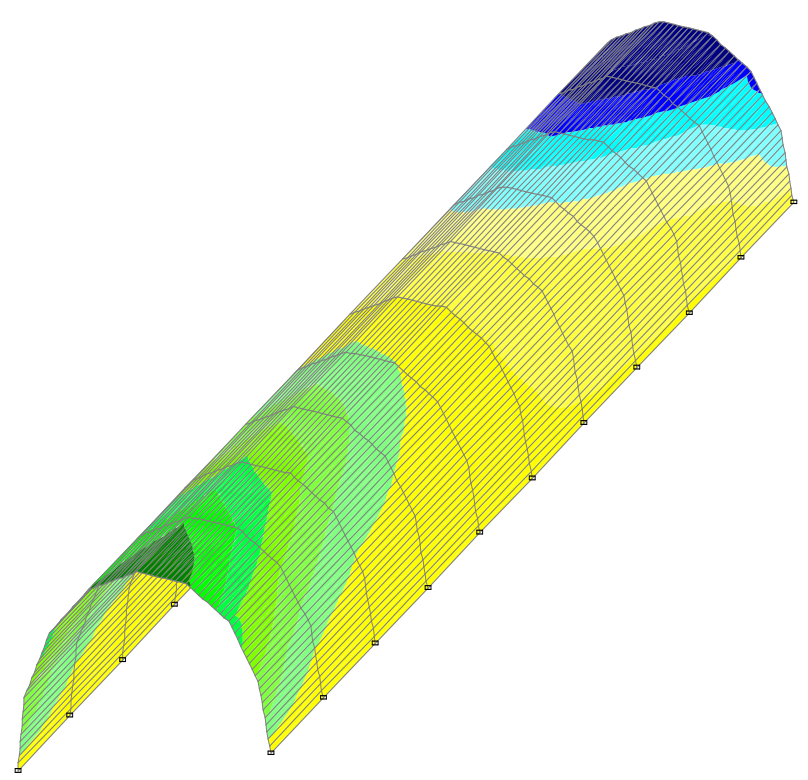

Fig. 5. Diagram of defect movements by the vertical along the discharge tunnel length.

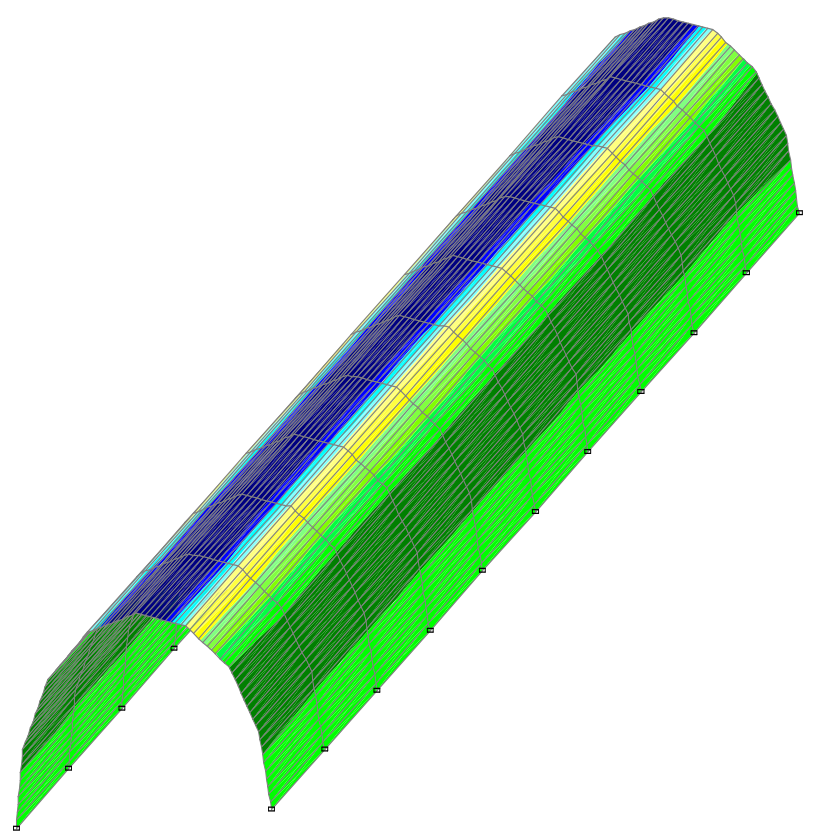

Fig. 6. Diagram of defect movements by the horizontal along the discharge tunnel length.

Movements by the horizontal and vertical in the cross direction bearing elements show insignificant displacements in support zones of horizontal reinforced concrete elements (figure 7,8). 


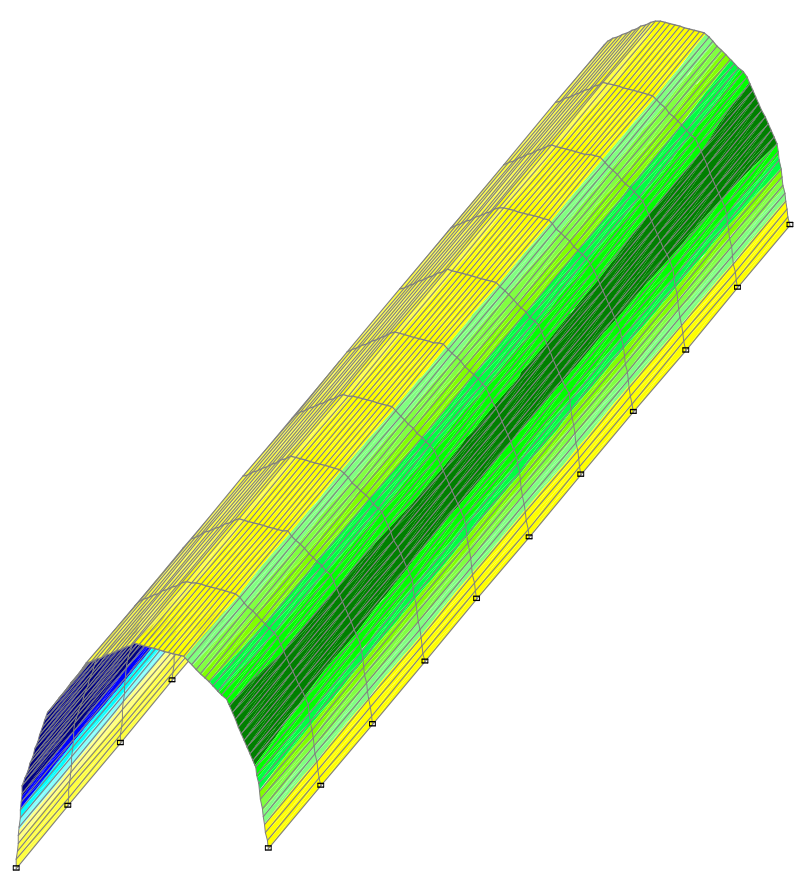

Fig. 7. Diagram of defect movements by the vertical in the cross direction the discharge tunnel length.

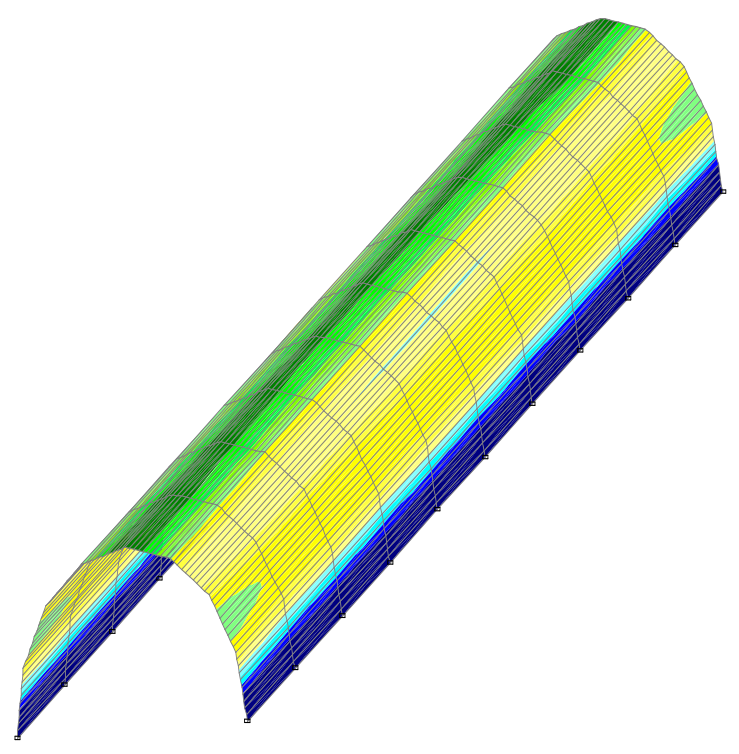

Fig. 8. Diagram of defect movements by the horizontal in the cross direction the discharge tunnel length.

In figure 9 a diagram of movements by the vertical of the discharge tunnel where a weak where a weak plaice of the reconstructed reinforced concrete discharge tunnel is vividly seen at the point of integration of horizontal and vertical elements when operating the structure and where longitudinal cracks can arise under the changes in technical parameters [11].

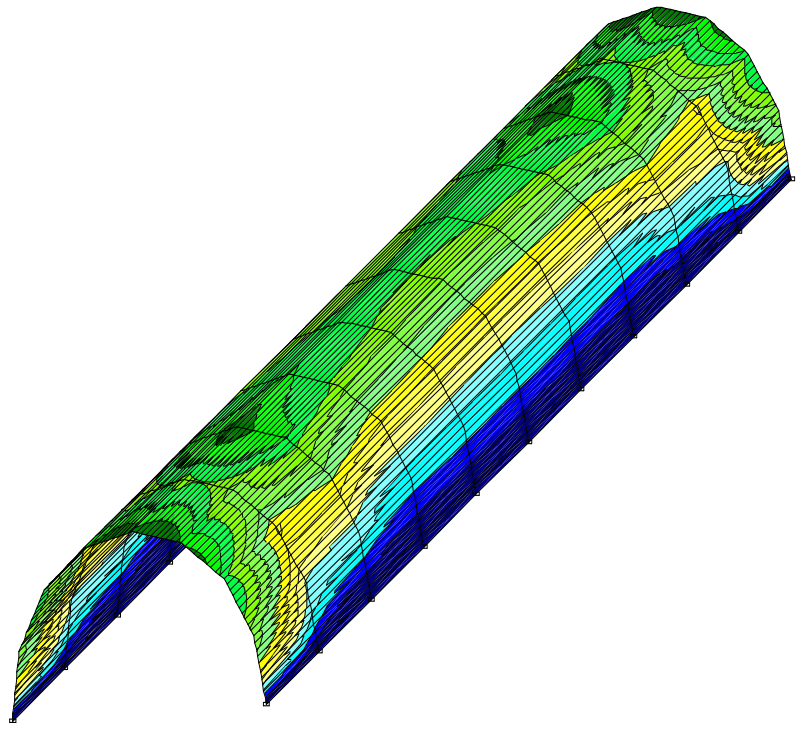

Fig. 9. Diagram of stresses by the vertical of the discharge tunnel.

To avoid this problem, it is necessary to strengthen the detected weak place of the reinforced concrete structure because its technical properties are at the dangerous threshiold of operation. It is also necessary to pay attention to strengthening reinforcing cage of water receiving sump (figure 10) [12].

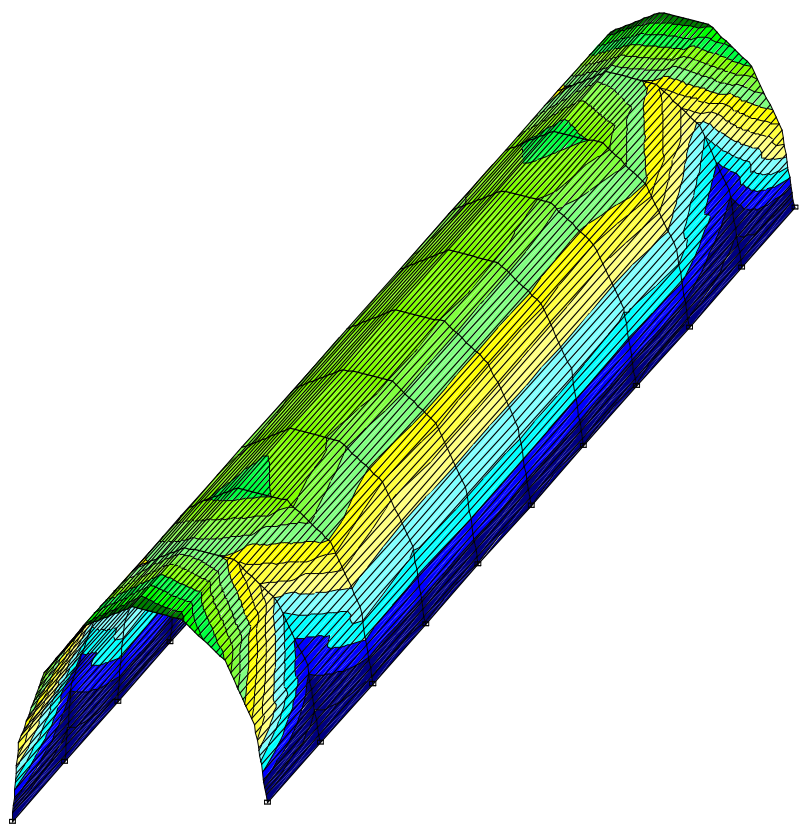

Fig. 10. Diagram of stresses by the vertical on discharge tunnel walls.

A diagram of stresses (figure 11) underlines weak rigidity of horizontal elements needed in additional reinforcement 
strengthening and in observations in the course of structure operation as well [13].

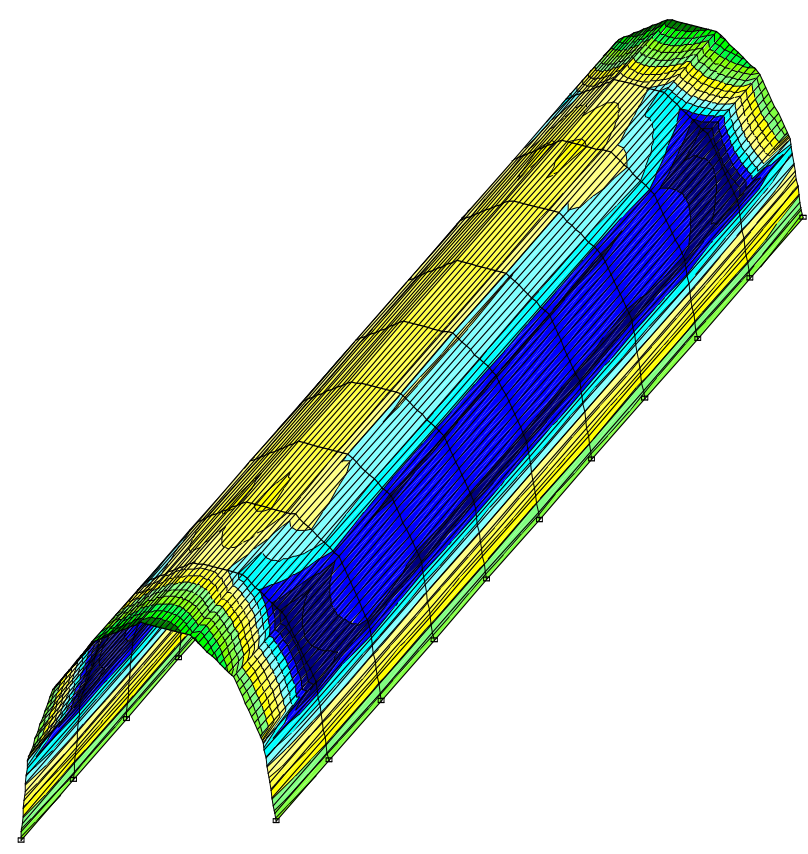

Fig. 11. Diagram of stresses by the horizontal on discharge tunnel walls.

As the results of comparison for diagrams of equivalent stress on von Mises show that the highest stresses arise in the discharge tunnel walls by the horizontal [14], namely at the lower part of the structure. This testifies to a rise of critical stresses at the base of the structure receiving not only water load, but the weight of the above lying soil as well as that of the whole structure [15].

The diagrams of equivalent stress on von Mises by the horizontal along and across of bearing elements also show the highest stresses arising in the support area of the structure on the base that are caused by deformations of bearing elements. There are also stresses in in the horizontal rein forced concrete elements.

\section{CONCLUSIONS}

The simulation of stresses and strained state carried out confirmed availability of significant safety margin in the bearing reinforced concrete element. Moreover, the values of absolute movements satisfy the accepted standards of hydraulic structure designing. Comparison of the diagrams for the equivalent stress on von Mises and movements showed that the highest stresses arose in the points of element support. These results testify to arising critical stresses in support areas that under head increasing can resulting destruction of the elements considered and loss of the bearing capacity for the whole structure.
Relations $(1,2)$ to determine moment cross-section of a fabricated water conveying tunnel of shaft spillway with outline close to the semicircular one. Making the fabricated water conveying tunnel of shaft spillway by expressions $(1,2)$ for discharges of 50-110 cbm with the head up to $10 \mathrm{~m}$ for small reservoirs results in reinforced concrete saving by $6-10$ $\%$ as compared with the typical rectangular elements.

\section{References}

[1] L. Dong, C. Lekakou, M. G. Bader, "Solid-mechanics finite element simulations of the draping of fabrics: a sensitivity analysis", Composites Part A: Applied Science and Manufacturing, vol. 31(7), pp. 639-652, 2000 .

[2] N. Frisch, D. Rose, O. Sommer, T. Ertl, "Visualization and preprocessing of independent finite-element meshes for car crash simulations", The Visual Computer, vol. 18(4), pp. 236-249, 2002.

[3] Ya. V. Volosukhin, M. A. Bandurin, "Questions of modeling the technical state of water distribution channels during operational monitoring”, Monitoring. Science and security, vol. 1, pp. 70-74, 2012.

[4] F. K. Abdrazakov, N. F. Ryzhko, S. N. Ryzhko, S. A. Horin, S. V. Botov, "Electricity consumption decrease at pump stations during watering by multi-support sprinkling units", Journal of Fundamental and Applied Sciences, vol. 10, pp. 1464-1481, 2018.

[5] I. F. Yurchenko, "Automatization of water distribution control for irrigation", International Journal of Advanced and Applied Sciences, vol. 4(2), pp.72-77, 2017.

[6] B. P. Chesnokov, O. V. Naumova, V. A. Strelnikov, F. K. Abdrazakov, B. A. Tronin, "Polyethylene production from granules using high voltage", International Journal of Applied Engineering Research, vol. 11, pp. 2140-2144, 2016.

[7] I. F. Yurchenko, "Information systems of managing water economy ameliorative complex", Bulletin of Russian Agricultural Science, vol. 1, pp. 12-15, 2016.

[8] Ya. V. Volosukhin, M. A. Bandurin, "Application of non-destructive methods during the operational monitoring of the technical condition of the channels of water-supply and irrigation systems", Monitoring. Science and security, vol. 2, pp. 102-106, 2012.

[9] H. De Gersem, K. Hameyer, "Convergence improvement of the conjugate gradient iterative method for finite element simulations", he International Journal for Computation and Mathematics in Electrical and Electronic Engineering, vol. 20(1), pp. 90-97, 2001.

[10] D. Danilov, B. Nestler, "Phase-field simulations of solidification in binary and ternary systems using a finite element method", Journal of Crystal Growth, vol. 275(1-2), pp. 347-362, 2005.

[11] A. V. Idesman, V. I. Levitas, D. L. Preston, J. Y. Cho, "Finite element simulations of martensitic phase transitions and microstructures based on a strain softening model", Journal of the Mechanics and Physics of Solids, vol. 53(3), pp. 495-523, 2005.

[12] O. G. Degtyareva, D. A. Dac'o, G. V. Degtyarev, A. D. Gumbarov, "Design in cae system of low-head weir tiled foundation sinking", Proceedings of the Kuban State Agrarian University, vol. 64, pp. 221226, 2017.

[13] A. Gajo, B. Loret, "Finite element simulations of chemo-mechanical coupling in elastic-plastic homoionic expansive clays", Computer Methods in Applied Mechanics and Engineering, vol. 192(31-32), pp. 3489-3530, 2003.

[14] B. I. Tomov, V. I. Gagov, R. H. Radev, "Numerical simulations of hot die forging processes using finite element method", Journal of Materials Processing Technology, vol. 153-154(1-3), pp. 352-358, 2004.

[15] U. Malm, M. Edoff, " $2 \mathrm{D}$ device modelling and finite element simulations for thin-film solar cells", Solar Energy Materials \& Solar Cells, vol. 93(6-7), pp. 1066-1069, 2009. 